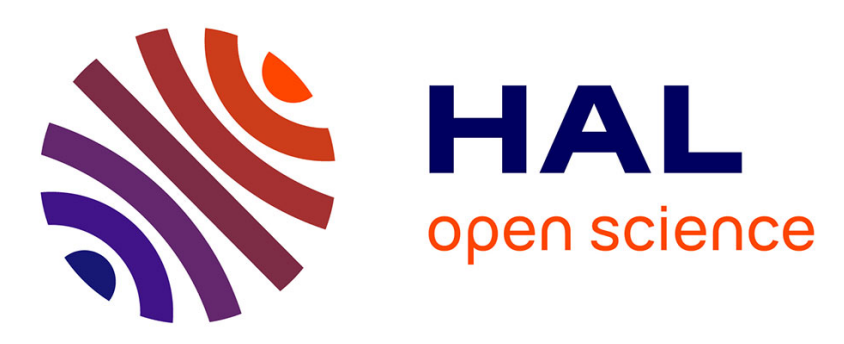

\title{
When your face describes your memories: facial expressions during retrieval of autobiographical memories
}

\author{
Mohamad El Haj, Mohamed Daoudi, Karim Gallouj, Ahmed Moustafa, \\ Jean-Louis Nandrino
}

\section{To cite this version:}

Mohamad El Haj, Mohamed Daoudi, Karim Gallouj, Ahmed Moustafa, Jean-Louis Nandrino. When your face describes your memories: facial expressions during retrieval of autobiographical memories. Reviews in the Neurosciences, 2018, 10.1515/revneuro-2018-0001 . hal-01710367

\section{HAL Id: hal-01710367 https://hal.science/hal-01710367}

Submitted on 15 Feb 2018

HAL is a multi-disciplinary open access archive for the deposit and dissemination of scientific research documents, whether they are published or not. The documents may come from teaching and research institutions in France or abroad, or from public or private research centers.
L'archive ouverte pluridisciplinaire HAL, est destinée au dépôt et à la diffusion de documents scientifiques de niveau recherche, publiés ou non, émanant des établissements d'enseignement et de recherche français ou étrangers, des laboratoires publics ou privés. 
When your face describes your memories:

\title{
facial expressions during retrieval of autobiographical memories
}

\author{
Mohamad EL HAJ ${ }^{1,2}$ \\ Mohamed DAOUDI ${ }^{3}$ \\ Karim GALLOUJ ${ }^{2}$
}

Ahmed A. MOUSTAFA ${ }^{4}$

Jean-Louis NANDRINO ${ }^{1}$

${ }^{1}$ Univ. Lille, CNRS, CHU Lille, UMR 9193 - SCALab - Sciences Cognitives et Sciences Affectives, F-59000 Lille, France

${ }^{2}$ Unité de Gériatrie, Centre Hospitalier de Tourcoing, Tourcoing, France

${ }^{3}$ IMT Lille Douai, Univ. Lille, CNRS, UMR 9189 -- CRIStAL -- Centre de Recherche en Informatique Signal et Automatique de Lille, F-59000 Lille, France

${ }^{4}$ School of Social Sciences and Psychology \& Marcs Institute for Brain and Behaviour, Western Sydney University, Sydney, Australia

Correspondence should be addressed to: Mohamad EL HAJ, Université de Lille 3, Département de Psychologie, Domaine du Pont de Bois, B.P 60149. 59653, Villeneuve d'Ascq, France. EMail: mohamad.elhaj@univ-lille3.fr 
Thanks to the current advances in software analysis of facial expressions, there is a burgeoning interest in understanding emotional facial expressions observed during the retrieval of autobiographical memories. This review describes research on facial expressions during autobiographical retrieval showing distinct emotional facial expressions according to the characteristics of retrieved memoires. More specifically, this research demonstrates that the retrieval of emotional memories can trigger corresponding emotional facial expressions (e.g., positive memoires may trigger positive facial expressions). Also, this study demonstrates variations of facial expressions according to specificity, self-relevance, or past vs. future direction of memory construction. Besides linking research on facial expressions during autobiographical retrieval to cognitive and affective characteristics of autobiographical memory in general, this review positions this research within the broader context research on physiological characteristics of autobiographical retrieval. We also provide several perspectives for clinical studies to investigate facial expressions in populations with deficits in autobiographical memory (e.g., whether autobiographical overgenerality in neurological and psychiatric populations may trigger few emotional facial expressions). In sum, this review paper demonstrates how evaluation of facial expressions during autobiographical retrieval may help understand the functioning and dysfunctioning of autobiographical memory.

Keywords: autobiographical memory; emotion; emotional facial expressions; facial expressions; facial expressions analysis; 


\section{Introduction}

Autobiographical memory refers to a knowledge base of personal information that covers both specific episodic memories and more general (semantic) information (Conway, 2005). Autobiographical memory has been intimately associated with emotional and affective processes (Schulkind and Woldorf, 2005). The relationship between autobiographical memory and emotion can be better understood by emphasizing research on facial expressions during autobiographical retrieval. The assessment of facial expressions as triggered by autobiographical retrieval is relatively a new area of study (El Haj et al., 2016a). The main aim of this review is to describe and position new area of research within the broader context of studies on cognitive and physiological characteristics of autobiographical retrieval. By doing so, we aim to demonstrate how the evaluation of facial expressions during autobiographical retrieval may help understand not only emotional and cognitive characteristics of this memory, but also physiological implications of autobiographical retrieval. We will also attempt to demonstrate how evaluation of facial expressions during autobiographical memory may help understand function of this memory. Because autobiographical memory is impaired in several neurological and psychiatric disorders, in the Discussion below, we provide suggestions on clinical implications of the evaluation of facials expressions during autobiographical retrieval.

To achieve these goals, we begin this review by describing current studies on the general physiological characteristics of autobiographical retrieval (i.e., brain, cardiovascular and electrodermal activities). The description of current knowledge on physiological activities during autobiographical retrieval also serves to provide some novel hypotheses to be tested by research on facial expressions. After that, we describe existing software systems allowing the analysis of facial expressions. We also detail research on facial expressions during autobiographical 
retrieval. More specifically, we describe research on facial expressions during 1) retrieval of general and specific autobiographical memoires, 2) retrieval of memories of high emotional intensity, i.e., self-defining memories, and 3) future thinking as, relatively to past thinking, future thinking seems to involve positive emotional reactions. In the discussion, we will briefly outline the main findings of research on facial expressions during autobiographical retrieval, and provide detailed suggestions for clinical and theoretical future research.

\section{Brain activities during autobiographical retrieval}

In this section, we describe neural networks that are involved in the early phases of autobiographical retrieval (e.g., when we search or access our memory system) and late phases of autobiographical retrieval (e.g., when we retrieve or relive a memory). This description may serve as a basis for future studies on facial expressions during early vs. late autobiographical retrieval. We also describe neural networks that are involved in the retrieval of general vs. specific autobiographical memories. We will also discuss evidence that distinct facial expressions have been also observed during general vs. specific autobiographical retrieval. We finally emphasize the involvement of the amygdala in autobiographical retrieval, as this brain structure has been intimately linked with emotional autobiographical memory.

Generally speaking, autobiographical retrieval has been associated with a "core network" of brain regions including the hippocampus, medial and ventrolateral prefrontal cortex, posterior cingulate, and temporoparietal junction (Conway et al., 1999, Maguire et al., 2001, Greenberg et al., 2005, St Jacques et al., 2017, Bonnici et al., 2012). More specifically, neuroimaging research reveals a distinction between brain regions that are active during early vs. late stages of autobiographical retrieval (Addis et al., 2004a, Daselaar et al., 2008). For instance, Daselaar et al. (2008) observed that early autobiographical retrieval elicited an increased activation of the 
hippocampus, medial prefrontal cortex and right prefrontal cortex, whereas late autobiographical retrieval was related to more activation of brain regions implied in retrieval of sensory information (e.g., visual cortex) and mental imagery (e.g., precuneus and inferior parietal cortex). The dissociation between brain areas that are activated in early vs. those late autobiographical retrieval was investigated by McCormick et al. (2015). The authors observed that the activation of the anterior and posterior hippocampus differed over the course of autobiographical retrieval, with the anterior hippocampus more broadly connected to other brain regions (e.g., frontal areas) in early retrieval and the posterior hippocampus more connected to these regions in late retrieval. Extending these findings, Inman et al. (2017) found strong connectivity between left hippocampus and right ventrolateral prefrontal cortex in early autobiographical retrieval, whereas late retrieval was characterized by a strong connectivity between occipital-parietal regions as well as by strong connectivity between dorsal frontalparietal regions.

Besides the distinction between brain areas that are involved in early vs. late stages of autobiographical retrieval, research has distinguished between brain areas that are involved in semantic (i.e., general) vs. episodic (i.e., specific) autobiographical retrieval. This distinction is based on neuropsychological evidence demonstrating that amnesic patients with damage to medial temporal lobe retrieve few autobiographical episodic details alongside relatively preserved ability to retrieve semantic information (Klein and Gangi, 2010, Steinvorth et al., 2005). Mirroring these findings, neuroimaging research has demonstrated that episodic autobiographical retrieval involves medial temporal lobe and as well as posteromedial and medial prefrontal cortices (Bonnici et al., 2012, Martinelli et al., 2013b); for instance, the activation of the hippocampus has been shown to increase parametrically with increased 
vividness of reliving and increased retrieval of contextual details (Addis et al., 2004b, Moscovitch et al., 2005). Semantic autobiographical retrieval, on the other hand, has been associated with an increased activation in the ventrolateral temporal cortex, including occipitotemporal fusiform gyrus and anterior temporal lobe (Addis et al., 2004a, Levine, 2004).

After describing neural underpinning of early vs. late autobiographical retrieval and episodic vs. semantic retrieval, we describe involvement of the amygdala in autobiographical memory. This is important as it provides additional insight into how autobiographical retrieval can trigger emotional activity. Generally speaking, the amygdala is regarded as an important brain site for modulating the salience of stimuli or events (Davis and Whalen, 2001), and its engagement is considered as a support of emotional processing and responding to both positive and negative stimuli (Everitt et al., 2003). The involvement of amygdala has been observed for emotional autobiographical memory, with healthy individuals typically exhibiting more amygdala activity during positive relative to negative autobiographical retrieval (Svoboda et al., 2006, Markowitsch et al., 2003). The involvement of amygdala in autobiographical retrieval has been also observed in patients with depression. For instance, Young et al. (2016) observed decreased left amygdala activity during retrieval of positive autobiographical information in participants with depression. Interestingly, the left amygdala activity correlated significantly with the severity of depression symptoms. The authors suggested that left amygdala hypoactivity during positive autobiographical recall is a state marker of depression.

Taken together, research suggests that different brain regions are activated according to the retrieval phase and specificity of autobiographical recall. As we will later emphasize, there is need for research on facial expressions during early vs. late autobiographical retrieval. Also, because prior research has associated autobiographical memory with specific brain activities, it 
will be of interest to evaluate the relationship between these activities and facial expressions during autobiographical retrieval. Based on the reviewed literature, one may expect a specific relationship between emotional facial expressions and the activity of the amygdala during autobiographical retrieval, which should be investigated in future research.

\section{Cardiovascular and electrodermal activities during autobiographical retrieval}

Unlike neural studies, little research has attempted to evaluate cardiovascular or electrodermal activities during autobiographical retrieval. In a pioneer study, Schaefer and Philippot (2005) evaluated cardiovascular and electrodermal activity during the retrieval of neutral and emotional autobiographical memories. Results demonstrated significant physiological changes during the retrieval of emotional compared to neutral memories; however, no significant changes were observed between positive and negative memory. Also, Marci et al. (2007) evaluated skin conductance and heart rate variability in participants who were exposed to autobiographical memories depicting anger, happiness, and sadness. Results demonstrated that anger was the only emotion to show a significant increase in sympathetic activity and a significant decrease in heart rate variability. The influence of autobiographical retrieval on physiological activity was also evaluated by Robertson et al. (2015) who found variations on blood pressure during retrieval of negative memories.

The effects of age and gender on cardiac reactivity during autobiographical retrieval was investigated by Labouvie-Vief et al. (2003). The authors evaluated heart rate during the retrieval of memories related to anger, fear, sadness, and happiness in younger and older adults. Results demonstrated that heart rate was generally lower in older adults than in younger participants; however, for anger and fear, these differences were more pronounced for women than for men. These findings suggest that the lower cardiac reactivity in older adults depends on gender and the 
category of emotion. Also, Foster and Webster (2001) showed that the age of encoding of emotional memory has an influence on the resulting psychophysiological arousal; the authors reported a significant correlation between skin conductance and age of encoding of both angry and happy autobiographical memories.

Taken together, the available evidence suggests variations of cardiovascular and electrodermal activities during autobiographical retrieval. These variations can be explained in the light of the somatic markers model (Damasio, 1999). According to this model, experiencing an emotional memory activates the somatic markers associated with it, particularly the visceral sensations associated with the memory. Interestingly, and as reviewed in this paper, physiological variations associated with autobiographical memories can be influenced by depression, age, and gender. As we will suggest in the discussion section, future research on facial expressions during autobiographical memory should also take into account variables related to depression, age, and gender.

After describing current knowledge on brain, cardiovascular and electrodermal activities during autobiographical retrieval, we describe software allowing analysis of facial expressions and detail research on facial expressions during autobiographical retrieval.

\section{Facial expressions}

In recent years, automated Facial Expression Recognition has aroused considerable interest. Earlier literature have mostly evaluated static faces grounding on either shape (geometry) or appearance features (Pantic and Rothkrantz, 2003). Recently, there have been a general shift to exploit the dynamics (motion) in facial expressions (Kacem et al., 2017, 
Zafeiriou et al., 2017) as conveying an expression is obviously a temporal process (Kacem et al., 2017). Automatic emotion analysis from dynamic facial expression is mainly guided by the discrete categorization into six basic classes, namely, anger, disgust, fear, happiness, sadness and surprise as proposed by Ekman (1992). Most of the benchmark public databases, such as the database of Kanade et al. (2000) follow this categorization.

Several software packages have been developed to describe emotional facial expressions in a manner that is cheaper, quicker, and equally reliable, when compared with human raters (Terzis et al., 2012). Examples of these software systems are Computer Expression Recognition Toolbox $^{\mathrm{TM}}$, InSight $\mathrm{SDK}^{\mathrm{TM}}$, and Intraface-Gui ${ }^{\mathrm{TM}}$. Research on facial expressions during autobiographical retrieval has used FaceReader ${ }^{\mathrm{TM}}$, a software that analyzes 500 key points in the face (den Uyl \& van Kuilenburg, 2005; Noldus Information Technologies, 2008). Facial analysis in this software occurs through three consecutive steps: 1) the software uses an algorithm to locate the face in images and videos, 2) the software synthesizes the face by describing the location of 500 key points and the facial texture of the area delineated by these points, then, 3) the software classifies facial expressions with an artificial neural network which automatically classifies the six basic emotions described by Ekman et al. (1998): neutral, happy, sad, angry, surprised, scared, and disgusted. Like other facial expressions software, FaceReader ${ }^{\mathrm{TM}}$ requires basic technical conditions (e.g., input frames with a resolution of at least $640 \times 480$ pixels) as well as some basic experimental conditions, for instance, the subject should be approximately 60 cm away from the camera, the face should also be approximately at the center (although facial expressions software can also process faces away of the center as long as they are around $60 \mathrm{~cm}$ away from the camera). In addition, the subject should assume a frontal face position with a neutral expression during calibration. Other environment conditions are required such as good 
illumination so face would be clearly visible, and, ideally, no light source behind the user (e.g., lamps, windows).

When analyzing facial expressions, FaceReader ${ }^{\mathrm{TM}}$ provides users with "action unit description" (e.g., whether the subject raises an eyebrow, whether the subject tightens or presses a lip) as these units may help to better understand the depicted emotion. Further, the software provides graphs showing the intensity of the recorded emotions and a pie chart representation of the percentage of an average expression, across all frames, of the following emotions: neutral, happy, sad, angry, surprised, scared, and disgusted. The pie chart also provides percentages of unknown states, referring to situations where the face could not be modeled (e.g., when the participant looks away from the camera). Similar analyses are proposed by Intraface (De la Torre et al., 2015), a publicly-available software package for facial expressions analysis. As illustrated in Figure 1, this software allows for the analysis of happy, surprised, sad, disgusted and neutral facial expressions.

After describing the software of facial analysis, in the following section we describe studies on facial expressions during autobiographical retrieval.

\section{INSERT FIGURE 1 APPROXIMATIVELY HERE}

\subsection{Studies on facial expressions during autobiographical retrieval}

\subsubsection{Facial expressions during retrieval of specific autobiographical memories}

In one study, El Haj et al. (2016a) asked 32 graduate/undergraduate students to retrieve three autobiographical memories, each of which was triggered by one of the following cue words: "happy", "sad", and "city". Cues were provided verbally and participants were invited to retrieve in detail an event related to the cue. The participants were instructed that the event had to 
be personally experienced in the past, and that the description had to be precise and specific (e.g., where and when the event occurred, who was present, what they were doing during this event, etc.). The experiment was recorded with an HD camera that was placed in front of the participants. The autobiographical retrieval was later analyzed regarding specificity, memories describing personal events situated in time and space, with a duration of less than one day, and accompanied by phenomenological details (i.e., perceptions, thoughts, feelings) were considered episodic autobiographical memories. The autobiographical retrieval was also analyzed with the FaceReader software. Analyses demonstrated a higher level of happy facial expressions in memories cued by the word "happy" than in those cued by the word "city" or by the word "sad". For sad facial expressions, a higher level of these was observed in memories cued by the word "sad" than by the word "city" or by the word "happy". For neutral facial expressions, a higher

level of these expressions was observed in memories cued by the word "city" than by the word "happy" or by the word "sad". Therefore, these findings suggest that emotional cues triggered the corresponding basic facial expressions (e.g., happy facial expression for memories cued by “happy”). Interestingly, results demonstrated more emotional facial expressions during episodic than during semantic retrieval, regardless of the emotional valence of cues. The latter finding is of interest because it demonstrates that specific autobiographical memories trigger significant emotional facial activity.

\subsubsection{Facial expressions during retrieval of self-defining memories}

To further understand the effects of retrieval of specific autobiographical memories on facial expressions, Gandolphe et al. (2017) evaluated these expressions during the retrieval of self-defining memories as these memories are associated with high emotional intensity (Singer et al., 2013). The authors invited twenty participants to recount five self-defining memories; 
participants were invited to remember specific events in their life, which they consider important to define who they are. Participants were also instructed that the memories should refer to an event that helps them understand who they are, these events should be also events they would share with someone if they wanted that person to understand them in a basic way. Following each memory retrieval, participants were invited to rate its emotional valence on the SelfAssessment Manikin scale, a nine-point pictorial scale that has been shown to be a valid and reliable assessment of subjective emotional experiences (Bradley and Lang, 1994). To investigate whether self-defining memories would trigger more emotional than neutral facial expressions, Gandolphe et al. (2017) compared facial emotional expressions (i.e., sum of six emotional expressions: happy, sad, angry, surprised, scared, disgusted) vs. neutral expressions during retrieval of these memories. The authors also compared the percentage of positive (happy and surprised) vs. negative facial expressions (sad, angry, scared, disgusted), as this categorization has been proposed by Ekman (1993). Finally, the authors analyzed the subjective emotional experience of memories, as rated by the participants on the Self-Assessment Manikin scale. Results showed more emotional than neutral facial expressions during the retrieval of selfdefining memories. Results also showed more positive than negative facial expressions during retrieval of self-defining memories. Results also showed the more occurrence of happy than remaining (sad, angry, surprised, scared, disgusted) emotional facial expressions during the retrieval of these memories. As for the subjective emotional evaluation of memories, as rated on the Self-Assessment Manikin scale, participants rated their self-defining memories as positive. These findings demonstrate the consistency between facial expressions and the emotional subjective experience of self-defining memories. 
The emotional facial expressions, as observed by Gandolphe et al. (2017) during retrieval of self-defining memories, can be interpreted in light of a theoretical assumption according to which these memories are believed to have the power to evoke physiological states similar to those experienced in the encoded events (Sutin and Robins, 2005). In other words, the emotional facial expressions, as observed by Gandolphe et al. (2017), can be considered as reflecting affective and motivational content of the encoded events. Also, Gandolphe et al. (2017) attributed the positive facial expressions during retrieval of self-defining memoires to meaning making (i.e., reflecting on the positive outcomes of a negative event). This phenomenon of "making things better" mirrors the more general notion of redemption sequences in the life story and research about "happy endings" to negative events (King et al., 2000), and "fading affect bias", that is, fading is greater for unpleasant than for pleasant emotions associated with autobiographical events (Skowronski et al., 2004, Walker et al., 2003) and the "wisdom of experience", that is wisdom to transform negative events to positive life situations (Sternberg, 1998, Bluck and Gluck, 2004). Therefore, the positive facial expressions, as observed by Gandolphe et al. (2017) during the retrieval of self-defining memories, provides physiological evidence to the assumption that autobiographical retrieval may serve to "making things better", at least on non-pathological populations.

\subsubsection{Facial expressions during future thinking}

Besides evaluating facial expressions during retrieval of past events, research has also evaluated these expressions during future thinking which is believed to trigger positive emotional reactions (El Haj et al., 2017a).

Remembering the past and imagining the future are inherently linked through different mechanisms, especially mental time travel, that is, the ability to project oneself mentally 
backwards through time to relive one's personal past or forward through time to pre-experience possible future events (Tulving, 1985, Tulving, 2002, Wheeler et al., 1997). Remembering the past and imagining the future rely on common brain pathways; research demonstrates an overlap in neural activity within prefrontal, medial-temporal lobe and posterior cortical regions during remembering past events and imagining future scenarios (Addis et al., 2007, Okuda et al., 2003, Szpunar et al., 2007). Further, patients with neurological dysfunction who are unable to remember events from their past demonstrate a corresponding deficit in projecting themselves into the future (Hassabis et al., 2007, Klein et al., 2002, El Haj et al., 2015b, El Haj et al., 2015a). Considering the relationship between past and future thinking, El Haj et al. (2017a) investigated facial expressions during the autobiographical retrieval and generation of future scenarios. In this study, 33 graduate/undergraduate students were invited to recount events in their lives and to imagine future events that might reasonably happen in the future. For all past and future events, participants were invited to be specific, that is, events had to have lasted/last no more than a day and details had to be provided (e.g., where and when the event occurred/will occur, who was/will be present, what they were/will be doing during this event). Following both conditions, participants were asked to rate the emotional valence of their past/future thinking on a five-point scale.

El Haj et al. (2017a) found that participants rated their future thinking as more positive than their past thinking. The authors also found more emotional than neutral facial expressions during imagining the future, and more specifically, more happy than sad, angry, scared, or disgusted facial expressions during imagining the future. Results also demonstrated more emotional facial expressions during imagining the future than during remembering the past. These findings were interpreted in the light of research showing a positive bias for imagining the 
future (Finnbogadóttir and Berntsen, 2013, Berntsen and Bohn, 2010, D'Argembeau and Van der Linden, 2004, Newby-Clark and Ross, 2003, Ross and Newby-Clark, 1998, Berntsen and Jacobsen, 2008). Indeed, it has been suggested that imagining the future plays a central role in maintaining a positive self-image (Rasmussen and Berntsen, 2013). This assumption is consistent with the positive illusion account, according to which people tend to imagine the future by setting new goals with the expectation that they will succeed, whereas when remembering the past, people are typically constrained by the reality imposed by events that have already occurred (Cacioppo and Gardner, 1999, Rasmussen and Berntsen, 2013). Therefore, and by demonstrating positive facial expressions during imagining the future, theEl Haj et al. (2017a) study provides physiological evidence to the psychological theories about the idyllic vision of the future.

Taken together, research demonstrates distinct emotional facial expressions according to the emotional valence/arousal and specificity of autobiographical retrieval (El Haj et al., 2016a), the self-relevance of the retrieved autobiographical memories (Gandolphe et al., 2017), and the (past vs. future) direction of autobiographical retrieval (El Haj et al., 2017a). Besides demonstrating how autobiographical retrieval can trigger distinct facials expressions, this research provides physiological evidence to psychological theories about the function and characteristics of autobiographical memory (e.g., that autobiographical retrieval may serve to “making things better").

\section{Discussion}

Autobiographical memory has been intimately associated with emotional and affective processing, and autobiographical retrieval is typically modulated by the self-relevance and 
emotional content of the retrieved memory (Conway, 2005). By describing research on emotional facial expressions during autobiographical retrieval, this review provides new evidence in support of the relationship between autobiographical memory and emotion. More specifically, this review highlights research demonstrating distinct emotional facial expressions according to the 1) emotional valence and specificity of autobiographical retrieval, 2) selfrelevance of the retrieved autobiographical memories and 2) past vs. future direction of autobiographical retrieval. Accordingly, this review emphasizes how emotional facial expressions may mirror specificity and self-relevance of autobiographical retrieval, as well as the direction of autobiographical retrieval. In our view, one function of emotional facial expressions, as observed during autobiographical retrieval, is to mirror the subjective experience of memory. Specific autobiographical memories are intimately associated with a subjective experience in which of past is mentally relived (Tulving, 2002), therefore, emotional facial expressions, as observed during the retrieval of specific autobiographical memory (Gandolphe et al., 2017, El Haj et al., 2016a), may mirror the subjective experience of these memories. Besides mirroring the subjective experience of memories, facial expressions may mirror the function of these memories. As demonstrated by Gandolphe et al. (2017), retrieval of self-defining memories can be associated with positive emotional facial expressions which may reflect meaning making of these memory, namely, how these memories serve to reflect on the positive outcomes of a negative event. Also, positive facial expressions during retrieval of self-defining memories may reflect the physiological states that was experienced in the encoded events. This suggestion can be supported by an assumption according to which self-defining memories have the power to evoke physiological states similar to those experienced in the encoded events (Sutin and Robins, 2005). Therefore, facial expressions can be considered as reflecting the ability to relive the 
emotional experience of the past. The same thing can be said for future thinking. As found in the study of El Haj et al. (2017a), the positive facial expressions during future thinking provide physiological evidence to the psychological theories about the idyllic vision of the future. Together, and in our view, facial expressions during autobiographical retrieval mirror emotional regulation goals as well as the emotional experience of autobiographical past and future thinking.

Besides demonstrating how facial expressions may mirror the subjective experience, selfrelevance, and emotional regulation of memories, research on facial expressions emphasizes new physiological implication of autobiographical retrieval. As previously illustrated, physiological activities during autobiographical retrieval have been typically evaluated with neuroimaging. Unlike neuroimaging, facial expressions analysis is a cheap and non-invasive physiological evaluation of autobiographical memory. This non-invasive characteristic makes facial expressions analysis an ideal tool to evaluate physiological activities during autobiographical retrieval in patients with autobiographical memory impairment. As we will highlight in the next section, autobiographical memory is negatively impacted by neurological and psychiatric disorders, an impact that can be better understood by evaluating facial expressions during autobiographical retrieval in these disorders.

\subsection{Facial expressions in populations with autobiographical impairment}

In this section, we briefly describe autobiographical memory impairment in several populations. We begin by describing the characteristics of autobiographical memory in normal and pathological aging (i.e., Alzheimer's Disease). We then describe characteristics of autobiographical memory in psychiatric populations, namely, in patients with addictive behavior, Korsakoff’s syndrome, schizophrenia, and depression. 
Several studies have reported difficulties in retrieving specific autobiographical memories in normal aging (Addis et al., 2008, Levine et al., 2002, Piolino et al., 2006, Piolino et al., 2010, St Jacques and Levine, 2007, Habermas et al., 2013, El Haj et al., 2013, El Haj et al., 2012a, El Haj et al., 2012b). However, self-defining memories in normal aging seems to be characterized by high specificity (El Haj et al., 2015c, Martinelli et al., 2013a). For instance, Singer et al. (2007) found that self-defining memories received higher ratings in vividness and importance in older than in younger participants. Further, when reporting their self-defining memories, in comparison to younger adults, older participants mentioned serious and meaningful topics involving achievements, relationships, child rearing, political events, illnesses, and deaths. Therefore, it would be of interest to evaluate whether normal aging would be characterized by high emotional facial expressions during the retrieval of self-defining memories.

In contrast to normal aging, Alzheimer's disease patients demonstrate important difficulties in retrieving specific autobiographical memories (El Haj et al., 2015d, Barnabe et al., 2012, Seidl et al., 2011, El Haj and Antoine, 2017, Ivanoiu et al., 2006). Therefore, it would be of interest to evaluate whether autobiographical retrieval in these patients may involve few emotional facial expressions. However, patients with Alzheimer's disease may demonstrate high emotional facial expressions during the retrieval of emotional memories, an assumption that can be supported by research demonstrating significant retrieval of emotional information in the disease. For instance, Philippi et al. (2015) found that emotional autobiographical memories were more specific than neutral ones in patients with Alzheimer's disease. The emotional characteristic of autobiographical memory in Alzheimer's Disease has been investigated in a study in which participants were asked to rate, after autobiographical retrieval, phenomenological characteristics of their memories (e.g., reliving, back in time, remembering, 
realness, visual imagery, auditory imagery, emotion, importance...) (E1 Haj et al., 2016b). Results showed that patients attributed high emotional valence for their memories. Therefore, research on facial expressions may help to reveal whether emotional autobiographical memories may trigger significant emotional facial expressions in patients with Alzheimer's disease.

The difficulty to retrieve specific autobiographical memories, is the hallmark of autobiographical retrieval in alcohol-dependence (Williams, 2006, Nandrino et al., accepted, Poncin et al., 2015, Whiteley et al., 2009). Interestingly, difficulties to retrieve specific memories is less observable when individuals are abstinent for a longer period (more than 6 months) than in recently detoxified patients (about 15 days). Therefore, it would be of interest to investigate emotional facial expressions during the retrieval of autobiographical memories in individuals abstinent for a longer period vs. those recently detoxified. Another suggestion is to evaluate facial expressions for recent vs. remote memories, this in light of research demonstrating that individuals with alcohol dependence typically recall fewer memories from their recent past and more memories from their early adulthood than healthy controls (Fitzgerald and Shifley-Grove, 1999). According to several studies, early memories are highly organized and protected from alcohol consumption (Nandrino et al., 2016, Nandrino et al., 2014). Further, it would be of interest to evaluate facial expressions during the retrieval of self-defining memories as these memories have been found to trigger high negative valence (Cuervo-Lombard et al., 2016). The same suggestion can be made for future thinking in light of research difficulties to construct specific future scenarios in alcohol-dependence (D'Argembeau et al., 2006).

Future research should also invesytigate facial expressions during autobiographical retrieval in Korsakoff's syndrome, an amnesic syndrome caused by chronic thiamine deficiency and alcohol abuse (Kessels and Kopelman, 2012, El Haj et al., 2016c, El Haj et al., 2017b). It 
would be of interest to evaluate whether autobiographical retrieval would trigger few emotional facial expressions. This in light of research demonstrating difficulties to retrieve specific autobiographical memories (Kopelman and Kapur, 2001, Kopelman et al., 1999, Kopelman et al., 1997, El Haj et al., 2016c). Research also demonstrates profound anterograde memory deficit (i.e., impaired ability to remember events that occurred after the onset of the syndrome) and retrograde amnesia (i.e., impaired ability to remember events that occurred before the onset of the syndrome) (Fama et al., 2012) in the syndrome. Research also demonstrates general impairment of the subjective experience of autobiographical recall in the syndrome (El Haj and Nandrino, 2017).

As for schizophrenia, one core affective characteristic of this disorder is that patients do not outwardly express emotions even when they report experiencing them (Kring and Moran, 2008). Thus, it would be of interest whether these patients may express any emotional facial expressions during autobiographical retrieval. One may expect for few emotional facial expressions during autobiographical retrieval in light of a body of research demonstrating autobiographical overgenerality in schizophrenia (D'Argembeau et al., 2008, McLeod et al., 2006, Riutort et al., 2003); an overgenerality that has been attributed to avoidance of remembering traumatic events (Ricarte et al., 2017). Few facial emotional expressions can be also expected for future thinking because schizophrenia has been also associated with difficulties to generate specific future scenarios (D'Argembeau et al., 2008). As for self-defining memories, although patients with schizophrenia recall a similar number of self-defining memories than controls (Raffard et al., 2009, Raffard et al., 2010), the contents of these memories are more focused on illness, trauma, and stigma (Raffard et al., 2009, Raffard et al., 2010, Berna et al., 
2011). It would be thus of interest to evaluate whether these memories would trigger negative facial expressions in patients with schizophrenia.

Negative facial expressions can be also expected during autobiographical retrieval in depression. One core characteristic of autobiographical retrieval in depression is the systematic bias that favors negative memories (Gotlib and Joormann, 2010, Dalgleish and Werner-Seidler, 2014), with faster access to negative events when prompted and a greater tendency to generate negative events when autobiographical retrieval is unconstrained (Lloyd and Lishman, 1975). Supporting these findings, negative memories in depression are typically intrusive and uncontrolled (Patel et al., 2007). Such pervasive preferential access to negative memories leads to the expectation for negative facial expressions during autobiographical retrieval.

Taken together, future research can benefit from facial expression analysis to evaluate whether autobiographical overgenerality would be characterized by few emotional facial expressions in Alzheimer's disease, alcohol-dependence, Korsakoff's syndrome and schizophrenia; the same research can be conducted to investigate future thinking in these populations. It would be also of interest to evaluate whether normal aging would be characterized by high emotional facial expressions during retrieval of self-defining memories, as well as during retrieval of emotional memories in Alzheimer's disease. Future research can also evaluate whether negative facial expressions would be observed during retrieval of self-defining memories in schizophrenia, and during autobiographical retrieval in depression.

\subsection{Facial expressions in healthy individuals}

Besides assessing facial expressions in clinical populations, future research can assess a crucial issue in the general population, namely, whether distinct facial expressions can be 
observed in early vs. late stages of autobiographical retrieval. As emphasized before in this article, distinct neuroanatomical networks are found to be engaged in early vs. late stages of retrieval, future studies may thus evaluate whether similar distinction can be made for facial expressions. Because late stages of autobiographical retrieval are typically characterized by emotional reliving of memories (Conway, 2005), one may expect high emotional facial expressions during these stages. Another venue for future research in general populations is to analyze facial expressions during autobiographical retrieval regarding personality structure. For instance, individuals high in agency (i.e., assertive individuals with a tendency to mastery and power) may demonstrate important emotional expressions during autobiographical retrieval. The reverse can be expected for individuals with experiential avoidance personality as those individuals tend to control or suppress unwanted internal events such as thoughts, feelings and emotions (Hayes et al., 1996). Regardless of personality differences in the general population, the relationship between brain activations and facial expressions during autobiographical retrieval is also worth investigation in future research. In a similar vein, it would be of interest to evaluate the relationship between facial expressions and cardiovascular/electrodermal activities during autobiographical retrieval.

One issue that should be considered by research on facial expressions during autobiographical retrieval is some shortcomings of facial analysis software systems. For instance, FaceReader calculates an average of thousands of faces from several face picture data bases (den Uyl, M., \& van Kuilenberg, 2005), and that average is used as the corresponding facial emotion expression template; this method might miss some emotional facial expressions that do not match the data bases.

\section{Conclusion}


To summarize, humans rely on facial expressions to communicate their affective and mental states. Facial expressions, as observed during autobiographical retrieval, may serve to communicate the affective content and/or the phenomenological characteristics (e.g., importance, vividness) of the retrieved memories. By discussing the current knowledge on facial expressions during autobiographical retrieval, we position this knowledge within the broader context of cognitive, physiological, and clinical characteristics of autobiographical retrieval. In our view, research on facial expressions during autobiographical retrieval may not only help understand the functioning of autobiographical memory but also dysfunction of this memory system. 


\section{References}

ADDIS, D. R., MCINTOSH, A. R., MOSCOVITCH, M., CRAWLEY, A. P. \& MCANDREWS, M. P. 2004a. Characterizing spatial and temporal features of autobiographical memory retrieval networks: a partial least squares approach. Neuroimage, 23, 1460-71.

ADDIS, D. R., MOSCOVITCH, M., CRAWLEY, A. P. \& MCANDREWS, M. P. 2004b. Qualities of autobiographical memory modulate hippocampal activation during retrieval: preliminary findings of an fMRI study. Brain Cogn, 54, 145-7.

ADDIS, D. R., WONG, A. T. \& SCHACTER, D. L. 2007. Remembering the past and imagining the future: common and distinct neural substrates during event construction and elaboration. Neuropsychologia, 45, 1363-77.

ADDIS, D. R., WONG, A. T. \& SCHACTER, D. L. 2008. Age-related changes in the episodic simulation of future events. Psychol Sci, 19, 33-41.

BARNABE, A., WHITEHEAD, V., PILON, R., ARSENAULT-LAPIERRE, G. \& CHERTKOW, H. 2012. Autobiographical memory in mild cognitive impairment and Alzheimer's disease: a comparison between the Levine and Kopelman interview methodologies. Hippocampus, 22, 1809-25.

BERNA, F., BENNOUNA-GREENE, M., POTHEEGADOO, J., VERRY, P., CONWAY, M. A. \& DANION, J.-M. 2011. Self-defining memories related to illness and their integration into the self in patients with schizophrenia. Psychiatry Research, 189, 49-54.

BERNTSEN, D. \& BOHN, A. 2010. Remembering and forecasting: The relation between autobiographical memory and episodic future thinking. Mem Cognit, 38, 265-78.

BERNTSEN, D. \& JACOBSEN, A. S. 2008. Involuntary (spontaneous) mental time travel into the past and future. Consciousness and Cognition, 17, 1093-1104.

BLUCK, S. \& GLUCK, J. 2004. Making things better and learning a lesson: experiencing wisdom across the lifespan. J Pers, 72, 543-72.

BONNICI, H. M., CHADWICK, M. J., LUTTI, A., HASSABIS, D., WEISKOPF, N. \& MAGUIRE, E. A. 2012. Detecting representations of recent and remote autobiographical memories in VmPFC and hippocampus. J Neurosci, 32, 16982-91.

BRADLEY, M. M. \& LANG, P. J. 1994. Measuring emotion: the Self-Assessment Manikin and the Semantic Differential. J Behav Ther Exp Psychiatry, 25, 49-59.

CACIOPPO, J. T. \& GARDNER, W. L. 1999. Emotion. Annual Review of Psychology, 50, 191-214.

CONWAY, M. A. 2005. Memory and the self. Journal of memory and language, 53, 594-628.

CONWAY, M. A., TURK, D. J., MILLER, S. L., LOGAN, J., NEBES, R. D., MELTZER, C. C. \& BECKER, J. T. 1999. A positron emission tomography (PET) study of autobiographical memory retrieval. Memory, 7, 679-702.

CUERVO-LOMBARD, C., RAUCHER-CHENE, D., BARRIERE, S., VAN DER LINDEN, M. \& KALADJIAN, A. 2016. Self-defining memories in recently detoxified alcohol-dependent patients. Psychiatry Res, 246, 533-538.

D'ARGEMBEAU, A., RAFFARD, S. \& VAN DER LINDEN, M. 2008. Remembering the past and imagining the future in schizophrenia. J Abnorm Psychol, 117, 247-51.

D'ARGEMBEAU, A. \& VAN DER LINDEN, M. 2004. Phenomenal characteristics associated with projecting oneself back into the past and forward into the future: influence of valence and temporal distance. Conscious Cogn, 13, 844-58.

D'ARGEMBEAU, A., VAN DER LINDEN, M., VERBANCK, P. \& NOEL, X. 2006. Autobiographical memory in non-amnesic alcohol-dependent patients. Psychol Med, 36, 1707-15.

DALGLEISH, T. \& WERNER-SEIDLER, A. 2014. Disruptions in autobiographical memory processing in depression and the emergence of memory therapeutics. Trends Cogn Sci, 18, 596-604. 
DAMASIO, A. R. 1999. The feeling of what happens: Body and emotion in the making of consciousness, New York, Houghton Mifflin Harcourt.

DASELAAR, S. M., RICE, H. J., GREENBERG, D. L., CABEZA, R., LABAR, K. S. \& RUBIN, D. C. 2008. The spatiotemporal dynamics of autobiographical memory: neural correlates of recall, emotional intensity, and reliving. Cereb Cortex, 18, 217-29.

DAVIS, M. \& WHALEN, P. J. 2001. The amygdala: vigilance and emotion. Mol Psychiatry, 6, 13-34.

DE LA TORRE, F., CHU, W. S., XIONG, X., VICENTE, F., DING, X. \& COHN, J. 2015. IntraFace. IEEE Int Conf Autom Face Gesture Recognit Workshops, 1.

EKMAN, P. 1992. An argument for basic emotions. Cognition and Emotion, 6, 169-200.

EKMAN, P. 1993. Facial expression and emotion. Am Psychol, 48, 384-92.

EKMAN, P., ROSENBURG, E. \& HAGER, J. 1998. Facial action coding system affect interpretation database (FACSAID).

EL HAJ, M. \& ANTOINE, P. 2017. Describe yourself to improve your autobiographical memory: A study in Alzheimer's disease. Cortex, 88, 165-172.

EL HAJ, M., ANTOINE, P. \& KAPOGIANNIS, D. 2015a. Flexibility decline contributes to similarity of past and future thinking in Alzheimer's disease. Hippocampus, 25, 1447-55.

EL HAJ, M., ANTOINE, P. \& KAPOGIANNIS, D. 2015b. Similarity between remembering the past and imagining the future in Alzheimer's disease: Implication of episodic memory. Neuropsychologia, 66, 119-25.

EL HAJ, M., ANTOINE, P. \& NANDRINO, J. L. 2016a. More emotional facial expressions during episodic than during semantic autobiographical retrieval. Cognitive, affective \& behavioral neuroscience, $16,374-81$.

EL HAJ, M., ANTOINE, P. \& NANDRINO, J. L. 2017a. Facial expressions triggered by imagining the future. J Integr Neurosci, 16, 483-492.

EL HAJ, M., ANTOINE, P., NANDRINO, J. L., GELY-NARGEOT, M. C. \& RAFFARD, S. 2015c. Self-defining memories during exposure to music in Alzheimer's disease. Int Psychogeriatr, 27, 1719-1730.

EL HAJ, M., ANTOINE, P., NANDRINO, J. L. \& KAPOGIANNIS, D. 2015d. Autobiographical memory decline in Alzheimer's disease, a theoretical and clinical overview. Ageing research reviews, 23, 183-92.

EL HAJ, M., CLÉMENT, S., FASOTTI, L. \& ALLAIN, P. 2013. Effects of music on autobiographical verbal narration in Alzheimer's disease. Journal of Neurolinguistics, 26, 691-700.

EL HAJ, M., FASOTTI, L. \& ALLAIN, P. 2012a. The involuntary nature of music-evoked autobiographical memories in Alzheimer's disease. Conscious Cogn, 21, 238-46.

EL HAJ, M., KAPOGIANNIS, D. \& ANTOINE, P. 2016b. Phenomenological Reliving and Visual Imagery During Autobiographical Recall in Alzheimer's Disease. J Alzheimers Dis, 52, 421-31.

EL HAJ, M., KESSELS, R. P., MATTON, C., BACQUET, J. E., URSO, L., COOL, G., GUIDEZ, F., POTIER, S., NANDRINO, J. L. \& ANTOINE, P. 2016c. Destination Memory in Korsakoff's Syndrome. Alcohol Clin Exp Res, 40, 1321-7.

EL HAJ, M. \& NANDRINO, J. L. 2017. Phenomenological characteristics of autobiographical memory in Korsakoff's syndrome. Conscious Cogn, 55, 188-196.

EL HAJ, M., NANDRINO, J. L., KESSELS, R. P. C., MATTON, C., BACQUET, J. E., URSO, L. \& ANTOINE, P. 2017b. Retrospective Time Perception in Korsakoff's Syndrome. J Neuropsychiatry Clin Neurosci, appineuropsych16100206.

EL HAJ, M., POSTAL, V. \& ALLAIN, P. 2012b. Music enhances autobiographical memory in mild Alzheimer's disease. Educational Gerontology, 38, 30-41.

EVERITT, B. J., CARDINAL, R. N., PARKINSON, J. A. \& ROBBINS, T. W. 2003. Appetitive behavior: impact of amygdala-dependent mechanisms of emotional learning. Ann N Y Acad Sci, 985, 233-50.

FAMA, R., PITEL, A. L. \& SULLIVAN, E. V. 2012. Anterograde episodic memory in Korsakoff syndrome. Neuropsychol Rev, 22, 93-104. 
FINNBOGADÓTTIR, H. \& BERNTSEN, D. 2013. Involuntary future projections are as frequent as involuntary memories, but more positive. Consciousness and Cognition, 22, 272-280.

FITZGERALD, J. M. \& SHIFLEY-GROVE, S. 1999. Memory and Affect: Autobiographical Memory Distribution and Availability in Normal Adults and Recently Detoxifed Alcoholics. Journal of Adult Development, 6, 11-19.

FOSTER, P. S. \& WEBSTER, D. G. 2001. Emotional memories: the relationship between age of memory and the corresponding psychophysiological responses. International Journal of Psychophysiology, 41, 11-18.

GANDOLPHE, M. C., NANDRINO, J. L., DELELIS, G., DUCRO, C., LAVALLEE, A., SALOPPE, X., MOUSTAFA, A. A. \& EL HAJ, M. 2017. Positive facial expressions during retrieval of self-defining memories. J Integr Neurosci.

GOTLIB, I. H. \& JOORMANN, J. 2010. Cognition and depression: current status and future directions. Annu Rev Clin Psychol, 6, 285-312.

GREENBERG, D. L., RICE, H. J., COOPER, J. J., CABEZA, R., RUBIN, D. C. \& LABAR, K. S. 2005. Co-activation of the amygdala, hippocampus and inferior frontal gyrus during autobiographical memory retrieval. Neuropsychologia, 43, 659-74.

HABERMAS, T., DIEL, V. \& WELZER, H. 2013. Lifespan trends of autobiographical remembering: episodicity and search for meaning. Conscious Cogn, 22, 1061-73.

HASSABIS, D., KUMARAN, D., VANN, S. D. \& MAGUIRE, E. A. 2007. Patients with hippocampal amnesia cannot imagine new experiences. Proc Natl Acad Sci U S A, 104, 1726-31.

HAYES, S. C., WILSON, K. G., GIFFORD, E. V., FOLLETTE, V. M. \& STROSAHL, K. 1996. Experiential avoidance and behavioral disorders: A functional dimensional approach to diagnosis and treatment. Journal of consulting and clinical psychology, 64, 1152-1168.

INMAN, C. S., JAMES, G. A., VYTAL, K. \& HAMANN, S. 2017. Dynamic changes in large-scale functional network organization during autobiographical memory retrieval. Neuropsychologia.

IVANOIU, A., COOPER, J. M., SHANKS, M. F. \& VENNERI, A. 2006. Patterns of impairment in autobiographical memory in the degenerative dementias constrain models of memory. Neuropsychologia, 44, 1936-55.

KACEM, A., DAOUDI, M., AMOR, B. B. \& ALVAREZ-PAIVA, J. C. 2017. A Novel Space-Time Representation on the Positive Semidefinite Con for Facial Expression Recognition. arXiv preprint arXiv:1707.06440.

KANADE, T., COHN, J. F. \& TIAN, Y. Comprehensive database for facial expression analysis. Automatic Face and Gesture Recognition, 2000. Proceedings. Fourth IEEE International Conference on, 2000. IEEE, 46-53.

KESSELS, R. P. \& KOPELMAN, M. D. 2012. Context memory in Korsakoff's syndrome. Neuropsychol Rev, 22, 117-31.

KING, L. A., SCOLLON, C. K., RAMSEY, C. \& WILLIAMS, T. 2000. Stories of Life Transition: Subjective WellBeing and Ego Development in Parents of Children with Down Syndrome. Journal of Research in Personality, 34, 509-536.

KLEIN, S. B. \& GANGI, C. E. 2010. The multiplicity of self: neuropsychological evidence and its implications for the self as a construct in psychological research. Ann N Y Acad Sci, 1191, 1-15.

KLEIN, S. B., LOFTUS, J. \& KIHLSTROM, J. F. 2002. Memory and temporal experience: The effects of episodic memory loss on an amnesic patient's ability to remember the past and imagine the future. Social Cognition, 20, 353-379.

KOPELMAN, M. D. \& KAPUR, N. 2001. The loss of episodic memories in retrograde amnesia: single-case and group studies. Philos Trans R Soc Lond B Biol Sci, 356, 1409-21. 
KOPELMAN, M. D., STANHOPE, N. \& KINGSLEY, D. 1997. Temporal and spatial context memory in patients with focal frontal, temporal lobe, and diencephalic lesions. Neuropsychologia, 35, 153345.

KOPELMAN, M. D., STANHOPE, N. \& KINGSLEY, D. 1999. Retrograde amnesia in patients with diencephalic, temporal lobe or frontal lesions. Neuropsychologia, 37, 939-58.

KRING, A. M. \& MORAN, E. K. 2008. Emotional response deficits in schizophrenia: insights from affective science. Schizophr Bull, 34, 819-34.

LABOUVIE-VIEF, G., LUMLEY, M. A., JAIN, E. \& HEINZE, H. 2003. Age and gender differences in cardiac reactivity and subjective emotion responses to emotional autobiographical memories. Emotion, 3, 115-126.

LEVINE, B. 2004. Autobiographical memory and the self in time: brain lesion effects, functional neuroanatomy, and lifespan development. Brain Cogn, 55, 54-68.

LEVINE, B., SVOBODA, E., HAY, J. F., WINOCUR, G. \& MOSCOVITCH, M. 2002. Aging and autobiographical memory: dissociating episodic from semantic retrieval. Psychol Aging, 17, 677-89.

LLOYD, G. G. \& LISHMAN, W. A. 1975. Effect of depression on the speed of recall of pleasant and unpleasant experiences. Psychol Med, 5, 173-80.

MAGUIRE, E. A., VARGHA-KHADEM, F. \& MISHKIN, M. 2001. The effects of bilateral hippocampal damage on $\mathrm{fMRI}$ regional activations and interactions during memory retrieval. Brain, 124, 1156-70.

MARCI, C. D., GLICK, D. M., LOH, R. \& DOUGHERTY, D. D. 2007. Autonomic and prefrontal cortex responses to autobiographical recall of emotions. Cogn Affect Behav Neurosci, 7, 243-50.

MARKOWITSCH, H. J., VANDEKERCKHOVE, M. M., LANFERMANN, H. \& RUSS, M. O. 2003. Engagement of lateral and medial prefrontal areas in the ecphory of sad and happy autobiographical memories. Cortex, 39, 643-65.

MARTINELLI, P., ANSSENS, A., SPERDUTI, M. \& PIOLINO, P. 2013a. The influence of normal aging and Alzheimer's disease in autobiographical memory highly related to the self. Neuropsychology, 27, 69-78.

MARTINELLI, P., SPERDUTI, M. \& PIOLINO, P. 2013b. Neural substrates of the self-memory system: new insights from a meta-analysis. Hum Brain Mapp, 34, 1515-29.

MCCORMICK, C., ST-LAURENT, M., TY, A., VALIANTE, T. A. \& MCANDREWS, M. P. 2015. Functional and effective hippocampal-neocortical connectivity during construction and elaboration of autobiographical memory retrieval. Cereb Cortex, 25, 1297-305.

MCLEOD, H. J., WOOD, N. \& BREWIN, C. R. 2006. Autobiographical memory deficits in schizophrenia. Cogn Emot, 20, 536-47.

MOSCOVITCH, M., ROSENBAUM, R. S., GILBOA, A., ADDIS, D. R., WESTMACOTT, R., GRADY, C., MCANDREWS, M. P., LEVINE, B., BLACK, S., WINOCUR, G. \& NADEL, L. 2005. Functional neuroanatomy of remote episodic, semantic and spatial memory: a unified account based on multiple trace theory. J Anat, 207, 35-66.

NANDRINO, J. L., EL HAJ, M., TORRE, J., NAYE, D., DOUCHET, H., DANEL, T. \& COTTENCIN, O. 2016. Autobiographical Memory Deficits in Alcohol-Dependent Patients with Short- and Long-Term Abstinence. Alcohol Clin Exp Res, 40, 865-73.

NANDRINO, J. L., GANDOLPHE, M. C., ALEXANDRE, C., KMIECIK, E., YGUEL, J. \& URSO, L. 2014. Cognitive and affective theory of mind abilities in alcohol-dependent patients: the role of autobiographical memory. Drug Alcohol Depend, 143, 65-73.

NANDRINO, J. L., GANDOLPHE, M. C. \& EL HAJ, M. accepted. Autobiographical memory compromise in individuals with alcohol use disorders: towards implications for psychotherapy research. Drug and Alcohol Review.

NEWBY-CLARK, I. R. \& ROSS, M. 2003. Conceiving the past and future. Pers Soc Psychol Bull, 29, 807-18. 
OKUDA, J., FUJII, T., OHTAKE, H., TSUKIURA, T., TANJI, K., SUZUKI, K., KAWASHIMA, R., FUKUDA, H., ITOH, M. \& YAMADORI, A. 2003. Thinking of the future and past: the roles of the frontal pole and the medial temporal lobes. Neuroimage, 19, 1369-80.

PANTIC, M. \& ROTHKRANTZ, L. J. 2003. Toward an affect-sensitive multimodal human-computer interaction. Proceedings of the IEEE, 91, 1370-1390.

PATEL, T., BREWIN, C. R., WHEATLEY, J., WELLS, A., FISHER, P. \& MYERS, S. 2007. Intrusive images and memories in major depression. Behav Res Ther, 45, 2573-80.

PHILIPPI, N., BOTZUNG, A., NOBLET, V., ROUSSEAU, F., DESPRES, O., CRETIN, B., KREMER, S., BLANC, F. \& MANNING, L. 2015. Impaired emotional autobiographical memory associated with right amygdalar-hippocampal atrophy in Alzheimer's disease patients. Front Aging Neurosci, 7, 21.

PIOLINO, P., COSTE, C., MARTINELLI, P., MACE, A. L., QUINETTE, P., GUILLERY-GIRARD, B. \& BELLEVILLE, S. 2010. Reduced specificity of autobiographical memory and aging: do the executive and feature binding functions of working memory have a role? Neuropsychologia, 48, 429-40.

PIOLINO, P., DESGRANGES, B., CLARYS, D., GUILLERY-GIRARD, B., TACONNAT, L., ISINGRINI, M. \& EUSTACHE, F. 2006. Autobiographical memory, autonoetic consciousness, and self-perspective in aging. Psychol Aging, 21, 510-25.

PONCIN, M., NEUMANN, A., LUMINET, O., VANDE WEGHE, N., PHILIPPOT, P. \& DE TIMARY, P. 2015. Disease recognition is related to specific autobiographical memory deficits in alcoholdependence. Psychiatry Research, 230, 157-164.

RAFFARD, S., D'ARGEMBEAU, A., LARDI, C., BAYARD, S., BOULENGER, J. P. \& VAN DER LINDEN, M. 2009. Exploring self-defining memories in schizophrenia. Memory, 17, 26-38.

RAFFARD, S., D'ARGEMBEAU, A., LARDI, C., BAYARD, S., BOULENGER, J. P. \& VAN DER LINDEN, M. 2010. Narrative identity in schizophrenia. Conscious Cogn, 19, 328-40.

RASMUSSEN, A. S. \& BERNTSEN, D. 2013. The reality of the past versus the ideality of the future: emotional valence and functional differences between past and future mental time travel. Mem Cognit, 41, 187-200.

RICARTE, J. J., ROS, L., LATORRE, J. M. \& WATKINS, E. 2017. Mapping autobiographical memory in schizophrenia: Clinical implications. Clin Psychol Rev, 51, 96-108.

RIUTORT, M., CUERVO, C., DANION, J. M., PERETTI, C. S. \& SALAME, P. 2003. Reduced levels of specific autobiographical memories in schizophrenia. Psychiatry Res, 117, 35-45.

ROBERTSON, S. M., SWICKERT, R. J., CONNELLY, K. \& GALIZIO, A. 2015. Physiological reactivity during autobiographical narratives in older adults: the roles of depression and anxiety. Aging Ment Health, 19, 689-97.

ROSS, M. \& NEWBY-CLARK, I. R. 1998. Construing the Past and Future. Social Cognition, 16, 133-150.

SCHAEFER, A. \& PHILIPPOT, P. 2005. Selective effects of emotion on the phenomenal characteristics of autobiographical memories. Memory, 13, 148-60.

SCHULKIND, M. D. \& WOLDORF, G. M. 2005. Emotional organization of autobiographical memory. Mem Cognit, 33, 1025-35.

SEIDL, U., LUEKEN, U., THOMANN, P. A., GEIDER, J. \& SCHRODER, J. 2011. Autobiographical memory deficits in Alzheimer's disease. J Alzheimers Dis, 27, 567-74.

SINGER, J. A., BLAGOV, P., BERRY, M. \& OOST, K. M. 2013. Self-defining memories, scripts, and the life story: narrative identity in personality and psychotherapy. J Pers, 81, 569-82.

SINGER, J. A., REXHAJ, B. \& BADDELEY, J. 2007. Older, wiser, and happier? Comparing older adults' and college students' self-defining memories. Memory, 15, 886-98.

SKOWRONSKI, J., GIBBONS, J., VOGL, R. \& WALKER, W. R. 2004. The Effect of Social Disclosure on the Intensity of Affect Provoked by Autobiographical Memories. Self and Identity, 3, 285-309.

ST JACQUES, P. L., CARPENTER, A. C., SZPUNAR, K. K. \& SCHACTER, D. L. 2017. Remembering and imagining alternative versions of the personal past. Neuropsychologia. 
ST JACQUES, P. L. \& LEVINE, B. 2007. Ageing and autobiographical memory for emotional and neutral events. Memory, 15, 129-44.

STEINVORTH, S., LEVINE, B. \& CORKIN, S. 2005. Medial temporal lobe structures are needed to reexperience remote autobiographical memories: evidence from H.M. and W.R. Neuropsychologia, 43, 479-96.

STERNBERG, R. J. 1998. A balance theory of wisdom. Review of General Psychology, 2, 347-365.

SUTIN, A. R. \& ROBINS, R. W. 2005. Continuity and correlates of emotions and motives in self-defining memories. J Pers, 73, 793-824.

SVOBODA, E., MCKINNON, M. C. \& LEVINE, B. 2006. The functional neuroanatomy of autobiographical memory: a meta-analysis. Neuropsychologia, 44, 2189-208.

SZPUNAR, K. K., WATSON, J. M. \& MCDERMOTT, K. B. 2007. Neural substrates of envisioning the future. Proc Natl Acad Sci U S A, 104, 642-7.

TERZIS, V., MORIDIS, C. N. \& ECONOMIDES, A. A. 2012. The effect of emotional feedback on behavioral intention to use computer based assessment. Computers \& Education, 59, 710-721.

TULVING, E. 1985. Memory and consciousness. Canadian Psychology/Psychologie Canadienne, 26, 1-22.

TULVING, E. 2002. Episodic memory: from mind to brain. Annu Rev Psychol, 53, 1-25.

WALKER, W. R., SKOWRONSKI, J. J. \& THOMPSON, C. P. 2003. Life is pleasant--and memory helps to keep it that way! Review of General Psychology, 7, 203-210.

WHEELER, M. A., STUSS, D. T. \& TULVING, E. 1997. Toward a theory of episodic memory: the frontal lobes and autonoetic consciousness. Psychol Bull, 121, 331-54.

WHITELEY, C., WANIGARATNE, S., MARSHALL, J. \& CURRAN, H. V. 2009. Autobiographical memory in detoxified dependent drinkers. Alcohol Alcohol, 44, 429-30.

WILLIAMS, J. M. 2006. Capture and rumination, functional avoidance, and executive control (CaRFAX): Three processes that underlie overgeneral memory. Cogn Emot, 20, 548-68.

YOUNG, K. D., SIEGLE, G. J., BODURKA, J. \& DREVETS, W. C. 2016. Amygdala Activity During Autobiographical Memory Recall in Depressed and Vulnerable Individuals: Association With Symptom Severity and Autobiographical Overgenerality. Am J Psychiatry, 173, 78-89.

ZAFEIRIOU, L., ZAFEIRIOU, S. \& PANTIC, M. Deep Analysis of Facial Behavioral Dynamics. Computer Vision and Pattern Recognition Workshops (CVPRW), 2017 IEEE Conference on, 2017. IEEE, 1988-1996. 


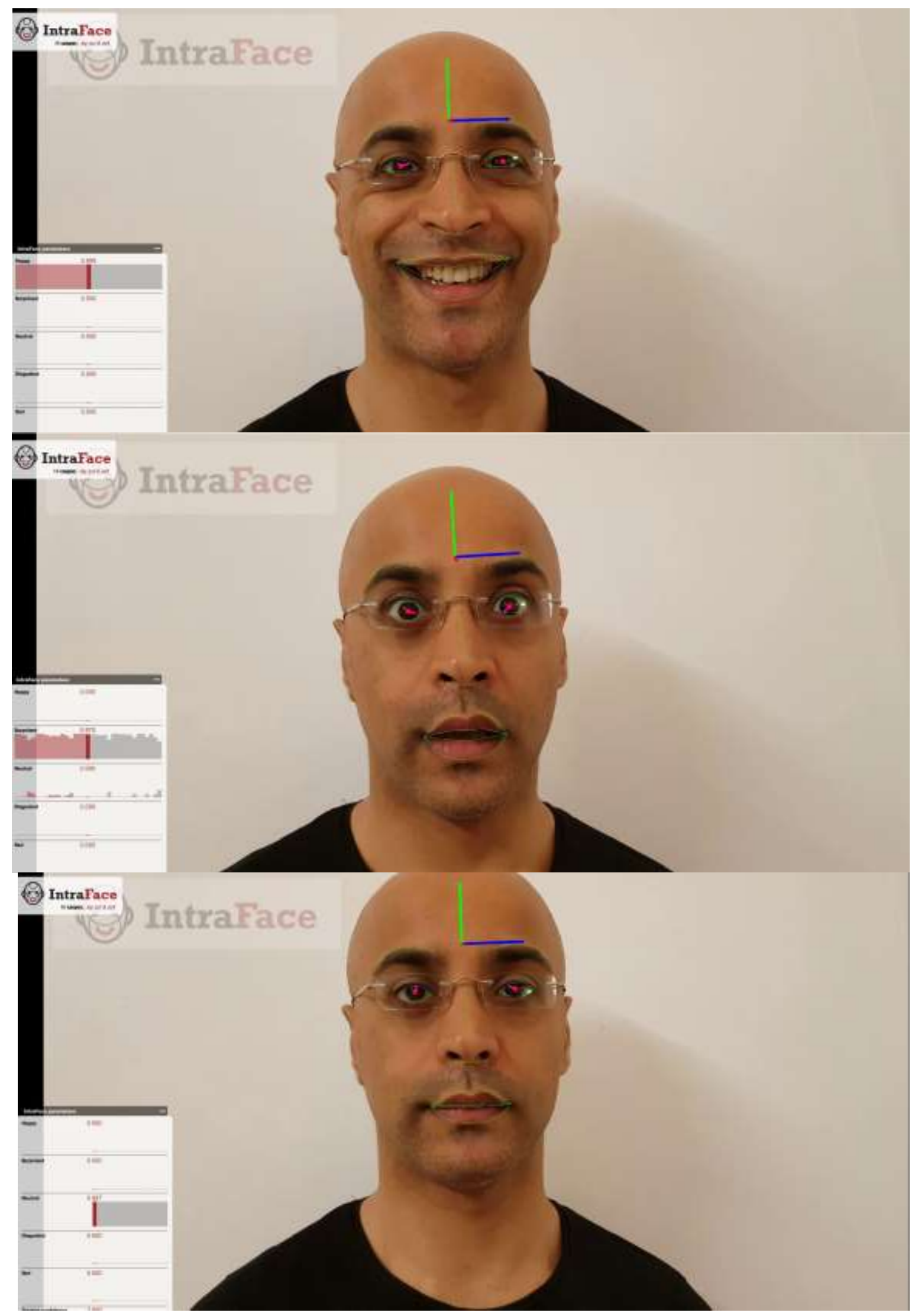




\section{Figure1.}

Facial expressions as analyzed by Intraface software. The software here depicts emotion expressed by the first author, from above to below, showing happy, surprise, and neutral expressions. The green and blue lines refer to zones (e.g., lips, eyebrow) that are mainly analyzed by the software. 